\title{
AN UNUSUAL CASE OF URGE INCONTINENCE DUE TO ARIPIPRAZOLE
}

\section{Serhat TUNC ${ }^{1}$, Ece BUYUKSANDALYACI ${ }^{2}$, Hamit Serdar BASBUG ${ }^{3}$}

${ }^{1}$ Department of Psychiatry, Kafkas University, Kars, TURKEY

US EPA ${ }^{2}$ Bakirkoy Training and Research Hospital for Psychiatry, Neurology and Neurosurgery, Department of Psychiatry, Istanbul, Turkey.

${ }^{3}$ Department of Cardiovascular Surgery, Kafkas University, Kars, TURKEY

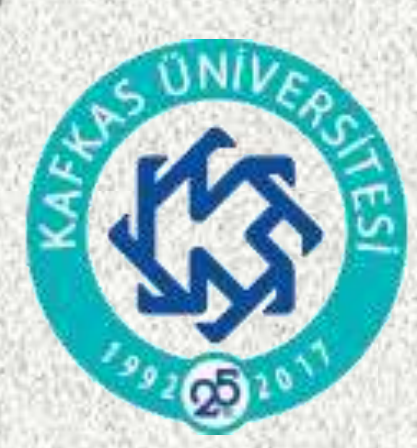

Urge incontinence is one of the adverse effects that can be observed after drug treatments. Urge incontinence is described as the involuntary loss of urine and can form hygiene or social trouble for affected patients. Aripiprazole is an atypical antipsychotic drug with antidepressant effects. Aripiprazole is partial agonist on dopamine D2 receptors and serotonin 5HT1A receptors which have extraordinary features in contrast to other antipsychotic drugs. It is used in various psychiatric disorders including schizophrenia, bipolar disorders, unipolar depression, and anxiety disorders. In this paper, a rare case of aripiprazole-induced urge incontinence in a schizophrenia patient was reported.

A 58-year-old female schizophrenia patient was admitted with the complaint of urinary incontinence after starting an antipsychotic aripiprazole $15 \mathrm{mg} /$ day one week ago for the first time.

The patient reported no complaint if she stopped the aripiprazole for trial purpose. She responded very well to anticholinergic drug trospium chloride $30 \mathrm{mg} /$ day which is used for urge incontinence. The aripiprazole treatment was thus discontinued. After the drug termination, urinary incontinence was interrupted.

Clinicians should keep in mind that aripiprazole can cause urinary incontinence that may lead to more troubles as it may affect patients compliance with the prescription. Further studies should be done to delineate the mechanism and whether this complication is dose-related or not.

Keywords: aripiprazole, drug side effects, urge incontinence 